\title{
Supply Chain System Integration in Retailing: A Case Study of LianHua
}

\author{
Guoling Lao and Lei Xing \\ School of Information Management and Engineering, Shanghai University of Finance and \\ Economics, Shanghai 200433, P.R. China gllao@shufe.edu.cn
}

\begin{abstract}
Supply Chain Management (SCM) is one of the most important concepts, which focuses on customer requirement and sets Core Company in the centre, integrating the suppliers, distributors and customers as a whole. Integration is the trend and advantage of SCM. It is necessary for the retail industry to introduce the concepts and methods of SC Integration Management. Through close cooperation and systematical integration with upper enterprises, retailers can effectively improve the operation level of enterprises, reduce cost and improve customer's service level. This thesis introduces SCM theory and development in retailing industry, and then discusses implementation of SC integration according to problems existing in Lian Hua Supermarket. Lian Hua will collaborate with IBM to do a project about supply chain integration. We analyze the information and put forward supply chain integration plan that includes a framework, transaction applications, an IT framework and operation service. We also give some suggestions after analyzing the results of Supply Chain Integration Management.
\end{abstract}

Keywords: EIS, SCM, Integration, Retailing

\section{THE CONCEPT OF SUPPLY CHAIN MANAGEMENT}

Because supply chain is a complex system, we should plan unitedly and manage harmoniously to have a good performance. The concept of Supply Chain Management is put forward in this environment. Various scholars have various opinions about Supply Chain Management, as well as Supply Chain. Jones and Riley [1] and Langeley and Houlcomb [2] explain the Supply Chain Management from the aspect of function chain, they argued that the key point of Supply Chain Management is Invetory Managemetn, and the supply chain is connected by procurement, production, stock, distribution and selling. Manordt and Harrington [3] studied the information flow in supply chain, which is a course for buyers and sellers to exchange information and data, and they argued that the information should be shared by all sides, not possessed exclusively by only one enterprise, in order that all enterprise in a supply chain can know the logistic situation and make decision more accurately. So the key of Supply Chain Management is transmitting and sharing information. Hewitt, Lambert and Cooper [4] argued that Supply Chain Management should be able to coordinate and unify all business process, including customer relationship management processes, customer service management process, need management

Please use the following format when citing this chapter:

Lao, G., Xing. L., 2007. in IFIP International Federation for Information Processing. Volume 254, Rescarch and Practical Issues of Enterprise Information Systems II Volume 1. eds. L. Xu. Tjoa A., Chaudhry S. (Boston: Springer). pp. $519-528$. 
process, order satisfaction process, production management process, production process, product research and marketing process, crap and returned purchase process, which is not limited to information flow management and logistic management.

\section{INTEGRATING THE SUPPLY CHAIN IN RETAILING INDUSTRY}

Supply Chain Integration is coordinating and making an effort for each other in all enterprises of supply chain, to enhance the overall competitive strength [5]. Current studies about supply chain integration in retailing industry are mostly focused in production planning, marketing channels, inventory management and cooperation. The main research achievements include: the analysis of prediction about selling amount of European food grocer through case observation by Johanna Smaros [6]; the application of design method called fuzzy object program in s constructing the Synergetic production and selling planning by Hasan Selim [7]; Jianxin (Roger) Jiao [8] introduces an associative classification-based recommendation system for personalization in B2C e-commerce applications; Bernhard [9] constructed the selling-distribution model of supply chain integration, explained the method that changing the key factories and capability indexes into the environment variables and analyzing how to use decision making system to improve the supply chain; Charles S. Tapiero [10] used NPQ model to analyze the risk and quality controlling of raw material suppliers and manufacturers; Caroline Emberson [11] studied the collaboration between the retailers and suppliers, expatiating on the competitive and cooperative relationship; Piet van der Vlist [12] studied the collaboration between retailers and suppliers in VMI.

In retailing industry, in order to manage more and more products and services effectively, retailers and companies in supply chain should change traditional business model, rebuild supply chain system and realize the integration of supply chain. The supply chain management is not mature in our country, so supply chain management can be solved not only by participators' self-adjusting, but by leaders' support and coordination.

\section{CASE STUDY: SC INTEGRATION OF LIANHUA SUPERMARKET}

\subsection{Brief Introduction of LianHua Supermarket}

Lian Hua supermarket organized in May, 1991, is first one supermarket characterized by chain-store operations. After the 14 year's development, Lian Hua created scale developing advantage, including big mall, supermarkets, and 
convienience stores, which are polynary complementation and progradation. Now, Lian Hua is a leader in Chain's retailing industry, having more than 3500 chain stores.

Lian Hua's current business consists of big mall, standard supermarkets and convenience stores.

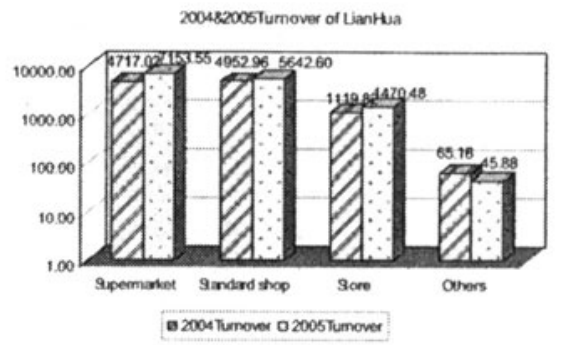

Figure 1. The Sales Turnover of Different Business

\subsection{Problem Analysis of Lian Hua Supermarket}

Through the analysis of the seven main operation procedures (order operation, receiving operation, returning operation, clearing operation, payment operation, obtaining business and searching operation, marketing operation) in Lian Hua's supply chain at that time, we discover that Lian Hua had established small-scale B2B platform in some business, and had certain application base, but some problems remain in the system and transaction operation, as in showing below:

(1) Ways of interaction

The platform at that time mainly provides a one-way information display through websites, and the suppliers just cooperate passively;

Lian Hua doesn't make its system butted with the suppliers' system, which affects big suppliers' response initiative;

(2) The function of the platform and its integrity

The function of the existing platform is imperfect, with too many interfaces and inadequate stability, security, and processing capability. Different suppliers face different interfaces and have different account numbers of Lian Hua.

(3) Application scope and management depth

Huge number of suppliers (over 8000 all together), but few are online and the charging standards are not unified. Lack support for the monitoring of key performance indicators and lack of information sharing mechanisms. Lack support for strategic plan of Group development.

(4) Difficult to coordinate with the Group Business Resource Integration

The Group needs to enhance its bargaining ability through joint procurement; 


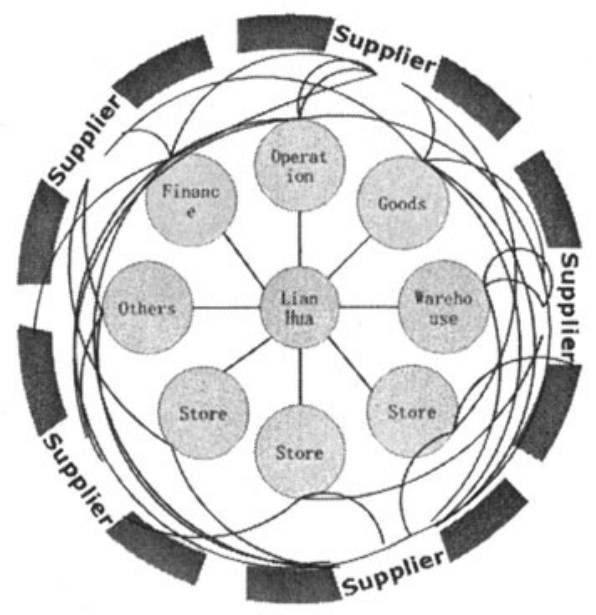

Figure 2. The Current Supplier Management Situation Analysis of Lian Hua

Analysis shows that the current supply chain has been unable to meet Lian Hua Group Co.'s needs of development. Based on the idea of integrated supply chain management, and taking into account the features of Lian Hua's retail chain, the author explored the application of integrated supply chain in the retailing industry. This exploration was made under the background of the implementation of supply chain integration project in Lian Hua and IBM. It considered the problem Lian Hua was facing and its actual demand, used IBM's supply chain management solution for reference, and implements the integrated supply chain management thought. The following illustration will be from the aspects of implementation strategy, solution, progress and evaluation.

\subsection{Exploration of the Implementation of Lian Hua Group Supply Chain Integration}

\subsubsection{Design of an Integrated Supply Chain}

Century Lian Hua Supermarket mainly sells daily products, processed foods at normal temperature, and fresh food. According to Fischer's product-based supply chain design strategy, daily products and processed foods at normal temperature are functional foods with stable, predictable demand and long lifecycle, so companies have to choose a supply chain which is more efficient-sensitive; while fresh food is innovative products with instable demand, so companies have to choose a supply chain which is more market-sensitive [13]. Therefore, the supply chain design is shown in the following table 1 : 
Table 1. Supply Chain Design for a Supermarket

\begin{tabular}{|c|c|c|}
\hline Supplychain & $\begin{array}{l}\text { Daily products, } \\
\text { pressed foods at normal } \\
\text { temperature }\end{array}$ & Fresh food, daily necessities \\
\hline main objective & $\begin{array}{l}\text { Ensure the supply with } \\
\text { lowest cost }\end{array}$ & $\begin{array}{l}\text { Quick response to market } \\
\text { demand to reduce the supply } \\
\text { shortage and excessive stock } \\
\text { loss }\end{array}$ \\
\hline $\begin{array}{c}\text { suppliers } \\
\text { selection criteria }\end{array}$ & Focus on cost and quality & $\begin{array}{l}\text { Focus on supplying speed, } \\
\text { flexibility, and quality }\end{array}$ \\
\hline $\begin{array}{l}\text { Inventory } \\
\text { strategy }\end{array}$ & $\begin{array}{l}\text { Accelerate inventory } \\
\text { turnover, and reduce } \\
\text { inventory quantity }\end{array}$ & $\begin{array}{l}\text { Determine proper purchasing } \\
\text { quantity }\end{array}$ \\
\hline $\begin{array}{l}\text { Predate of } \\
\text { delivery }\end{array}$ & $\begin{array}{l}\text { Try to shorten the predate } \\
\text { within the scope of cost }\end{array}$ & $\begin{array}{l}\text { Reduce the predate through } \\
\text { initiative investment }\end{array}$ \\
\hline
\end{tabular}

\subsubsection{The Integrated Supply Chain Platform of Lian Hua Supermarket}

\section{(1) Platform framework}

Guided by the above established strategy, the author provides a B2B overall supply chain management solution for Century Lian Hua. The solution includes four main parts: platform building, suppliers' promotion, customer service of suppliers and retailers, and platform maintenance. This solution provides two users of the supply chain platform-Century Lian Hua and its supplier-a full range of service. The overall function diagram of this solution is as following:

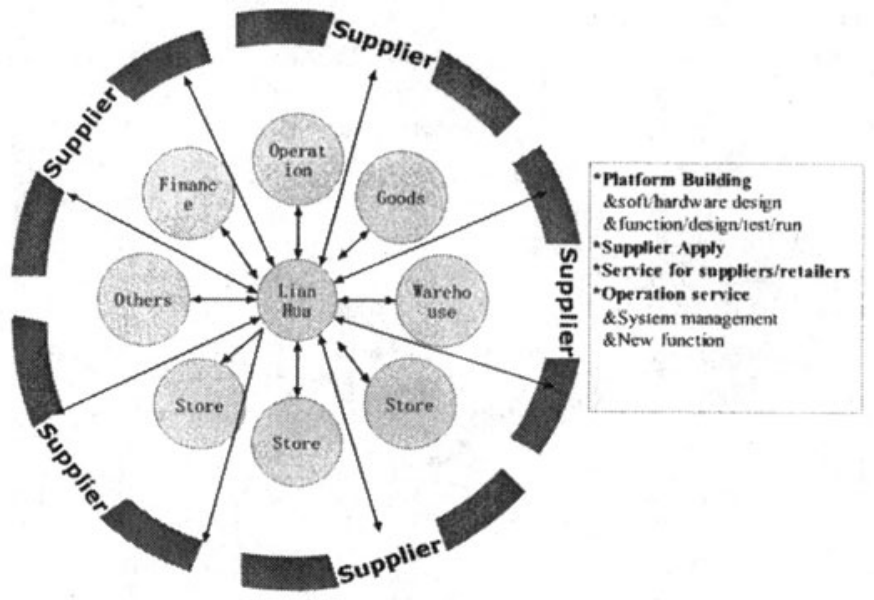

Figure 3. Overall Function of Platform

We can see from this figure, the overall solutions not only includes suggestion work of technology structure, including software and hardware planning, installing and platform function planning, the customers' services provided by retailers, management and maintenance of the platform system and the development and 
application of new function, ensuring this platform's quick response to changing transaction.

\section{(2) The transaction application}

This platform provide with following application support to Lian Hua and its suppliers:

Suppliers' contracts and products research: members' basic information (company information/ factory information), products electronic catalog and contracts checking;

Inquiring quoted price and bargain: new products invoice, quoting files, file management and file limits of authority;

Purchasing and returned purchasing: purchase order receiving/checking, receiving report receiving/checking, returned purchasing inform report receiving/checking, returned purchasing inform replying, sales promotion cooperation inform and sales promotion cooperation replying.

Receiving/selling/inventory management and inventory performance management: sales inventory summary, detail checking, order short delivery report, order overdue, submitted order overdue, summary of returned goods and particulars checking.

Delivering management and payment tasks: an account payable checking, deduction statement checking, deduction projects collection checking, obligated balance checking, bank cable transfer accounts checking, payment on invoice checking and cost of delayed goods checking.

\section{(3) IT structure}

From the perspective of IT technology, this framework provides an Internet-based platform for the trusteeship council, sets up an integrated supply chain management system for users from Century Lian Hua and vendors:

Different vendors log on to the platform through dial-up, ADSL, GMB and other access side, System Provide security identification for each vendor to confirm the identity of users and ensure that information security; Meanwhile, original applications procedures of Century Lian Hua such as the internal network and headquarters of systems, shop operating systems, payment systems, and ERP also integrated with the supply chain management system, and ensured the safety of application through network firewalls. The solution to the functional structure is shown in the figure 5 .

Network data center from IBM in Shanghai provided this supply chain management with trusteeship service for hardware and platform software; meanwhile application systems provided by IBM's strategic partnership B\&S Link were integrated into the entire System through Gateway.

Without large-scale change to original system, Century Lian Hua and its suppliers acquired a highly reliable, on-demand integrated supply chain management platform. So, in this solution, subsystems between Century Lian Hua, IBM, B\&S Link had also created a highly integrated "partnership", together supported the core business of Century Lian Hua. 


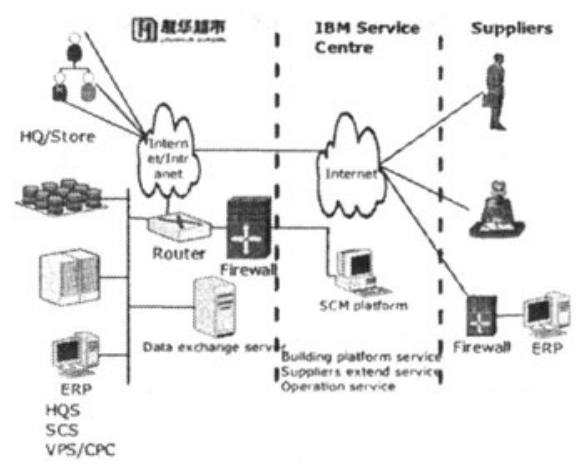

Figure 4. Solutions to the Functional Structure

\section{(4) Operation service}

As stated earlier, this solution is an overall plan, which included not only technology platform build, but also the promotion and services after the build platform. The following chart shows the solution to the contents of operation service. IBM, and B\&S Link and Century Lian Hua together in close cooperation, after the completion of the first phase of the platform and build functional lines, immediately developed corresponding steps to promote vendor. Along with the continuous build of platform functions, the promotion process is continuous follow-up. At the same time of continued progress of reciprocating in "build-promote-rebuild-re-promote", IBM and B\&S Link provided Century Lian Hua and its suppliers with a full range of customer services and maintenance platform management services.

Platform built: Major steps mainly include function planning, function descriptions and demand collection, differences analysis, needs identification, hardware and software investment, development and testing, user acceptance, internal training, and on the line. According to the plan, the two phases of Century Lian Hua will be completed in succession in the 18 months.

Vendors' promotion: Major steps include plan promotion echelon, exploration and selected for manufacturers and sites, delivery of documentation preparation, Vendors contact, platform training, environment preparation, vendors training, and tracking and services for usage situation

Platform operation: adopt three lines service systems to provide Century Lian Hua and suppliers with services, concretely include that the first-line provides operation instructions, function explanations, business advice and platform window; the second line provides a platform issue management; the third line provides platform application with the function maintenance and platform systems management for software / hardware / network. 


\section{Lian Hua Supermarket Supply Chain Logistics Distribution Centre in Integration}

\section{(1) Build a modern logistics distribution centre}

As already introduced major Lian Hua Group Distribution Center, Logistics center uses advanced information technology and automated systems, including automatic transmission, automatic pallet lifts system, automatic sorting and handling system, and the systems which load and unload height adjustment plate for cargo platform installed on the platform, all significantly improving Lian Hua Supermarket distribution and overall operating efficiency. Meanwhile, the Group has been adopting wireless handheld terminals, bar code reading technology and wireless signal transmission technology and other hi-tech on such main links as receiving, display, warehouse transfer. Effectively establishing a headquarters and the retailing network and quickly providing real-time operational information facilitate headquarters at any time control the operation. Also, the logistics distribution center installs GPS tracking device and discharge end plates in delivery Vehicles. In addition to real-time handling the passers-delivery vehicles operation, further it improves the discharging efficiency of the shop.

\section{(2) Shorten the logistics flow}

(1) Shorten the time on the way.

Give full play to the network in the role of marketing; organize purchase according to different demand of different customers, improve marketable commodity rate. Only by sticking to formulate marketing can reasonable commodity structure be able to establish. Only having good commodity structure, can effectively reduce the stay time from purchase, storage, display to sale. With the shortest time in-transit (including transportation, distribution, inventory time), send product to the customers.

(2) Reduce garments ration link, Shorten the logistics distance. Effective methods is reducing distribution links and Shortening logistics corridor.

(3) Use logistics service form third parties

Lian Hua choosing logistics services outsourcing should experience processes as following:

(1) Inner analysis and estimation of Lian Hua. Make certain the relationship between operation gains and outsourcing; Make certain what logistics services need to outsourcing; collect large material and data to make sure that what outsourcing logistics operation can bring the fast and the best return; adequately communicate with specific operational departments.

(2) Estimate its own demand, and chose service providers. Store out its own demand in detail and completely, use bidding mode to choose suitable logistics service providers, analyze and chose each enterprise data.

(3) The implementation and management of outsourcing. You should keep touch with the business performance of the outsourcing all the way, and exchange your proposal with suppliers immediately, also you should help your employee adapt the new business style.

(4) The alliance strategy of Lian Hua Supermarket with its suppliers 
If you want to build an effective and successful supply chain, the key is strategy alliance of retailers and manufactures also distributors. Lian Hua Group wants to set up the collaboration with its suppliers, it should follow below:

(1) Lian Hua should establish the demand analysis of collaboration with its suppliers

The foundation of establish the strategy alliance include belief each other, improve the information sharing between the chain, the operation is better than operate respectively, and everyone should follow the basic operation rule, also the regular of the alliance. That is to say, Lian Hua should consider its condition and demand first, and then establish a demand report that fit for it.

(2) Confirm the standard and select the partners

(3) Lian Hua establish the formal symbiosis with its manufactures and distributors

(4) Implement and enforce the relationship between strategy partners

The figure below illustrates the theory model of strategy alliance between Lian Hua and its suppliers.

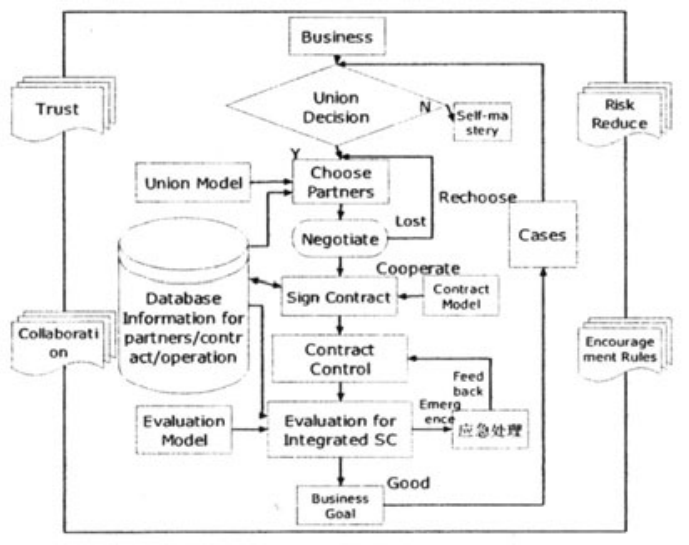

Figure 5. Theory Model for the Union between LianHua and Others

\section{CONCLUSIONS}

Now, the industry of retail is still in its development phase and the enterprise are all not strong in our country, they may in inferior position in the fierce global competition, there is a big gap between them and the topping global companies. We think the key of improving their competitive capability is combining themselves with all other companies and establish the Supply Chain Web. But actually, the Supply Chain Management in our country just involved the supply chain information management system of a single enterprise, the enterprise and its suppliers are still use the old and out the system's style to communicate with each other, it should enforce the collaboration of the supply chain. Aimed at the feature of Lian Hua, we propose 
we should pay attention to several problems when we implement the supply chain integrating.

(1) Break the traditional concept and establish the consciousness of win-win

(2) Pay attentions to belief, promises and flexibility protocol

(3) Enforce the core competitive capability

(4) Know and adopt collaboration technology correctly

(5) Recombine the supply chain in the right time

\section{REFERENCES}

1. A.B. Christian and J. Jayanth, Supply Chain Management: A Strategic Perspective, International Journal of Logistics Management. Volume 8, Number 1, pp.15-34, (1997).

2. G.P. Cachon and P.H. Zipkin, Competitive and cooperative inventory policies in a twostage supply chain (Fuqua school of business, Duker university, 1997).

3. F. Chen, Z. Drezner, J.K. Ryan, and D.S. Levi, Quantifying the Bullwhip Effect in a Simple Supply Chain: the Impact of Forecasting, Lead Times, and Information, Management Science. Volume 46, Number 3, pp.436-443, (2000).

4. A. Akintoye, G. McIntosh, and E. Fitzgerald, A Survey of Supply Chain Collaboration and Management in the UK Construction Industry, European Journal of Purchasing \& Supply Management. Volume 6, pp.159-168, (2000).

5. K. Petrson and L. Cecere, Supply Collaboration is a Reality - but Proceed with Caution, $A$ SCET. Volume 6, Number 3, (2001).

6. J. Smaros, Forecasting collaboration in the European grocery sector: Observations from a case study, Journal of Operations Management. Volume 25, Number 3, pp.702-716, (2007).

7. H. Selim, C. Araz, and I. Ozkarahan, Collaborative production-distribution planning in supply chain: A fuzzy goal programming approach, Transportation Research Part E: Logistics and Transportation Review. http://doi:10.1016/j.tre.2006.11.001 (Accessed February 14, 2007).

8. Y. Zhang and J. Jiao, An associative classification-based recommendation system for personalization in B2C e-commerce applications, Expert Systems with Applications. Volume 33, Number 2, pp.357-367, (2007).

9. B.J. Angerhofer and M.C. Angelides, A model and a performance measurement system for collaborative supply chains, Decision Support Systems. Volume 42, Number 1, pp.283-301, (2006).

10. C.S. Tapiero, Consumers risk and quality control in a collaborative supply chain, European Journal of Operational Research. Volume 182, Number 2, pp.683-694, (2007).

11. A. Emberson and J. Storey, Buyer-supplier collaborative relationships: Beyond the normative accounts, Journal of Purchasing and Supply Management. Volume 12, Number 5, pp.236-245, (2006).

12. P. Van der Vlist and R. Broekmeulen, Retail consolidation in synchronized supply chains, Zeitshrift fur Betriebswirtschaft. Volume 76, pp.165-176, (2006).

13. $\mathrm{X}$. Li and $\mathrm{Y}$. Tian, Analysis on retailing supply chain rebuilding in China, Business Research. Number 1, pp.1-3, (2000). 